\title{
Tecendo cultura com mediações que unem corpo, saúde e lazer
}

Tânia Mara Vieira Sampaio*

Resumo: A metáfora da colcha de retalhos abre a reflexão sobre os corpos que roçaram nos tecidos com suas histórias de vida e seus dribles à morte, se aconchegaram nas experiências plurais, constituindo-se em cultura. As palavras, nossos retalhos, serão dentre as demais formas de linguagens as grandes artesãs do diálogo entre corpo, cultura e saúde. O lazer será experimentado como um fio possível de alinhavar e costurar relações, tanto pelo potencial de ser uma expressão da cultura na qual o corpo pode experimentar a transgressão, quanto pela de não sucumbir à expropriação promovida pela economia de mercado. Palavras-chave: Relações mente-corpo. Características culturais. Qualidade de vida. Atividades de lazer.

Retalhos de pano e suas histórias de vida o tecido de flores do vestido da menina a listra que serviu de camisa para o avô, o xadrez da calça do tio, o preto-liso do vestido de festa

a flanela do pijama de quem adoeceu. os muitos retalhos, há muito, guardados esconde da lembrança seu tempo de andanças

nos corpos em movimento,

nos momentos da dança cotidiana (Tânia Mara)

\section{INTRODUÇÃO}

Seria a metáfora da colcha de retalhos uma inspiração para refletirmos sobre corpo cultura e saúde? É muito possível que sim, pois os corpos que passaram pelos tecidos dão depoimentos

* Docente no Mestrado em Educação Física da UNIMEP. Membro do Grupo de Pesquisa em Lazer (GPL). Formada em Pedagogia. Mestrado e Doutorado em Ciências da Religião. E-mail: tsampaio@unimep.br

Movimento, Porto Alegre, v.12, n. 03, p. 73-96, setembro/dezembro de 2006 
de suas histórias de vida, de seus dribles à morte e de sua construção de cultura. Simultaneamente sinalizam corpos saudáveis em convívio com corpos doentes, os quais se aconchegaram nos tecidos macios dos pijamas e camisolas. Estas histórias e movimentos do corpo agora estão tecidas artesanalmente na combinação com retalhos de roupas de festa, de cotidiano, de trabalho, de brincadeiras infantis, da primeira noite de namoro da menina, dos vestígios do tempo que não pára, mas que recorre ao passado para aninhar no presente as brechas da utopia.

As palavras, entre as demais formas de linguagens comunicativas dos seres humanos, são as grandes artesãs da cultura. Por meio delas, retalhos de mundos e horizontes podem ser percebidos como amplos ou reduzidos, já afirmava Ludwig Wittgenstein (1968, p.111), ao dizer que "os limites de minha linguagem denotam os limites do meu mundo". As palavras, como linguagens simbólicas privilegiadas no estabelecimento das relações humanas compõem de modo misterioso a sua capacidade de estabelecer pontes, de indicar proibições, de anunciar imagens de mundos ainda não vistos, de anunciar sonhos, de denunciar ausências, de revelar presenças, enfim, as palavras são mediações fundamentais para tecer relações entre os corpos. Desse modo, não poderia ser diferente nosso percurso aqui senão o de nos propomos a entrelaçar as palavras corpo-cultura-saúde e seus simbolismos construtores de cultura, alinhavados com o fio do lazer.

A experiência humana é apreendida por meio do universo simbólico da linguagem. As palavras mais do que o que dizem em si mesmas carregam um universo simbólico que as transcendem mediando à relação humana com a realidade.

Não me parece fácil encadear idéias que além de bem articuladas possam também contribuir comunicando sentido de vida para quem as lê. A indignação cotidiana com uma organização cultural que desqualifica os muitos corpos para preservar a vida de alguns salta no caminho como exigência de que nossos textos acadêmicos

Movimento, Porto Alegre, v.12, n. 03, p. 73-96, setembro/dezembro de 2006. 
sejam mais do que revisões de saberes importantes acumulados na história da humanidade.

Os corpos maltratados, descartados e sofridos se impõem diante dos meus olhos e em alguma medida freiam meus dedos no teclado. A incidência elevada deles nas estatísticas, sua despersonalização, sua quantificação e redução aos espaços que outros corpos não circulam precisa ser nomeada de saída não como vitimação da maioria da população brasileira ou do mundo. Basta que esteja em foco, como realidade da qual não se pode desligar se quisermos de fato tratar de corpo e saúde no universo cultural plural em constante construção no qual nos movemos. Ainda que as denúncias possam e precisem ser feitas, há uma subversão dos corpos no reinventar a saúde no cotidiano que em muito supera, tanto a tentativa da ciência positivista em dominar os conhecimentos sobre a saúde do corpo para afastá-lo da morte quanto à mercadorização em que se transformou a saúde na economia de mercado capitalista.

O percurso desta reflexão quer desvelar os corpos e suas compreensões de saúde, não raras vezes ocultados por um sistema que traça discursos normativos sobre saúde ignorando (ou melhor, desejando homogeneizar) a pluralidade de construções de sentido dos corpos na cultura afirmando a vida, rindo na cara da morte que para o sistema parece estar muito mais próxima dos corpos dada sua aposta no sacrifício necessário (isto é, morte da vítima) como condição sine qua non para que se dê o progresso tecnológico e científico pensado para a modernidade. (SAMPAIO, 2006)

Nesse texto, o corpo ${ }^{1}$ quer revelar-se a partir das histórias dos pequenos quadrados de tecido que se dispõe para armar-se

1 Não pretende-se incorrer no equívoco de tomar o conceito corpo como categoria a reforçar dualismos, mas, sim, para expressar sua totalidade, por isso, o termo corporeidad será também utilizado simultaneamente ao termo corpo, implicando esta totalidade da experiência humana de estar no mundo, o que não pode prescindir do corpo identificáve na relação com outros corpos.

Movimento, Porto Alegre, v.12, n. 03, p. 73-96, setembro/dezembro de 2006. 
em um bela colcha de retalhos. De corpos que se revelam e corpos que se cobrem, se aquecem, se embelezam, se sentem fortalecidos pelas representações dos tecidos... disso este texto quer falar.

O corpo em seu movimento cotidiano, através de diversas linguagens, anuncia seus desejos e sentidos. Criando cultura, cultivando projetos e sonhando horizontes proclama a vida com dignidade, afirma sua saúde na contramão de um sistema que multiplica as formas do morrer. Desse modo, a cultura será compreendida como uma construção social significativa para os seres humanos a partir de suas relações, o que exige que se considere a diversidade e pluralidade como sua marca fundamental. Segundo Ernst Cassirer (1972, p.50-51) o ser humano está aberto ao processo de construção cultural por necessitar da mediação simbólica para organizar sua existência no mundo. Isto é, ele:

Já não vive num universo puramente físico, mas num universo simbólico. A linguagem, o mito, a arte e a religião são parte deste universo. São os vários fios que tecem a rede simbólica, a teia emaranhada da experiência humana. [...] Já não

é dado ao homem enfrentar imediatamente a realidade; não pode vê-la, por assim dizer, face a face. A realidade fisica parece retroceder proporcionalmente, à medida que avança a atividade simbólica do homem. [...] Razão é um termo muito pouco adequado para abranger as formas da vida cultural do homem em toda sua riqueza e variedade. Mas todas estas formas são simbólicas. Portanto, em lugar de definir o homem como um animal rationale, deveríamos defini-lo como animal symbolicum. [grifo nosso] (CASSIRER, 1972, p. 50-51)

\section{A CULTURA COMO RESULTADO DE CORPOS EM MOVIMENTO}

E é sempre melhor o impreciso que embala do
que o certo que basta,

Wovimento, Porto Alegre, v.12, n. 03, p. 73-96, setembro/dezembro de 2006. 
Porque o que basta acaba onde basta, e onde acaba não basta.

E nada que se pareça com isto devia ser o sentido da vida. (Álvaro de Campos) $)^{2}$

É preciso considerar o movimento dos corpos para afirmar sentidos significativos de suas relações com potencial de criar cultura. Sem dúvida, os movimentos dos corpos, ainda que motivados por sons em cadência de continuidade, não podem abdicar de identificar as descontinuidades e os momentos históricos distintos que constituem a cultura. As dimensões da história anterior e da ação no presente em sua mútua interpelação anunciam que a cultura é dinâmica e está em constante construção. Segundo Clifford Geertz (1989) apud Jocimar Daólio (2004, p.7):

A cultura é a própria condição de vida de todos os seres humanos. É produto das ações humanas, mas é também processo contínuo pelo qual as pessoas dão sentido às suas ações. Constitui-se em processo singular e privado, mas é também plural e público. É universal, por que todos os seres humanos a produzem, mas é também local, uma vez que é a dinâmica específica de vida que significa o que o ser humano faz. A cultura ocorre na mediação dos indivíduos entre si, manipulando padrões dos indivíduos entre si, manipulando padrões de significados que fazem sentido num contexto especifico.

O corpo em seu movimento acolhe os anseios de sentido da existência possibilitando a re-significação de linguagens fortes e importantes que carregam a afirmação da identidade de um grupo social. Os distintos grupos sociais que compõem a sociedade não desejam sua organização do modo predominante em que, muitas vezes, está construída. O modo dominante de organização da vida

2 Poema de Fernando Pessoa no pseudônimo de Álvaro de Campos.

Movimento, Porto Alegre, v.12, n. 03, p. 73-96, setembro/dezembro de 2006. 
não representa à única e imutável forma de pensar a cultura. Dessa forma, o movimento de resistência, de contracorrente à lógica dominante é uma das marcas da experiência humana no mundo.

Os corpos posicionam-se porque este é um lugar de poder, por excelência, o controle sobre a vida passa pelo corpo, mantê-lo sob algumas prisões e cerceamentos são garantias de vidas mais abundantes e farturosas para alguns. Por isso, no foco de debate sobre a cultura os corpos não poderiam deixar sua centralidade.

Considerando que os diversos processos culturais são construções coletivas na tensão entre os poderes dominantes que organizam a economia, a política, a educação, a religião, a ciência, a saúde... e os grupos sociais mesmo enfraquecidos pelo sistema se organizam em contracorrentes, há que se estudar em que medida as corporeidades se relacionam transformando resistência, transgressão e provisoriedade em movimentos culturais os quais se valem das brechas da cultura dominante para reverter, ou no mínimo questionar os discursos normativos que buscam organizar a corporeidade.

A cultura, essa organização social marcada pelas relações sociais de poder, em seu movimento dinâmico, muitas vezes é palco de processos de apropriação da experiência relevante de alguns grupos sociais na intenção de expropriá-los de sua força. Por isso, é importante compreendê-la como processo dinâmico, plural, transitório, marcado por continuidades e descontinuidades. Contudo, um processo que não pode se desvincular da corporeidade humana e seu constante processo de relações.

E esta opção fundamenta-se na compreensão de que é por meio desta dimensão, a corporeidade, que se organiza a existência no mundo. Afinal, a pessoa busca conhecimentos e vivencia seus desejos a partir dos reflexos da realidade sobre seu corpo. Um processo de construção de sentidos, marcados por movimentos e momentos dos corpos que se organizam no cotidiano por meio de um amplo e complexo conjunto de relações sociais expressas na cultura.

O interesse está em analisar os movimentos que comunicam Movimento, Porto Alegre, v.12, n. 03, p. 73-96, setembro/dezembro de 2006. 
o complexo jeito humano de construir seus sentidos e organizar sua cultura. Enfim, relacionar-se. Trata-se de uma opção metodológica a pergunta pelo movimento que faz este corpo; por um lado, para evitar abstrações sobre a realidade e, por outro, para não perder a riqueza dos detalhes que indicam os vários jeitos de enfrentar as situações. Está no corpo, em sua exterioridade perceptível, a condição dos seres vivos construírem suas culturas, não apenas pelas reflexões, mas também as muitas linguagens expressas através dos gostos, dos sussurros, dos cheiros, das trocas de olhares, dos adornos, das imagens, dos jogos de sedução, dos prazeres, das dores... desatadas pelos diversos sentidos da corporeidade, que ocupa espaço e tempo concretos promovendo mediações simbólicas pluridimensionais.

A presente organização de parâmetros de análise introduz o cotidiano como o locus da pluralidade da organização simbólica da comunicação humana. Assim, o cotidiano abarca a complexa articulação da experiência humana e é admitido como o espaço de relações sociais em suas distintas esferas. Não se reduz ao âmbito doméstico ou a espaços desprovidos de positividade política no que tange aos enfrentamentos ou transformações sociais. Segundo Ágnes Heller (1991, p. 59-60):

\begin{abstract}
A vida cotidiana em si mesma não é "alguma coisa" senão a experiência vital moderna e compartida na qual se baseia nossa intersubjetiva constituição do mundo [...]. Por experiências vitais não pretendo referir-me só aos atos, acontecimentos, e sucessos, senão também ao marco geral de significados, visões de mundo, instituições de significação que guiam, sintetizam e ordenam o processo mesmo da experiência.
\end{abstract}

\title{
3 CORPO E SAÚDE UMA COSTURA POSSÍVEL NA COLCHA DA CULTURA
}

A saúde encontra-se nessa reflexão como uma das possibilidades de sentido dos corpos em sua construção cultural. Falar de

Movimento, Porto Alegre, v.12, n. 03, p. 73-96, setembro/dezembro de 2006. 
saúde é dar expressão ao corpo. É escutá-lo como corpo expressivo, sensível, vulnerável, transcendente, marcado por experiências pessoais singulares e coletivas que podem ser de inclusão ou de exclusão ao defrontar-se no cotidiano.

Para Jacques Le Goff $(1985$, p. 7,8) o jogo da saúde e da doença pertence à história, acima de tudo pelo confronto que este binômio apresenta aproximando ou não o corpo de sua finitude, "a doença pertence à história, em primeiro lugar porque não é mais do que uma idéia, um certo abstracto numa 'complexa realidade empírica', e porque as doenças são mortais. [...] A doença pertence não só à história superficial dos progressos científicos e tecnológicos como também à história profunda dos saberes e das práticas ligadas às estruturas sociais, às instituições, às representações, às mentalidades." Desse modo, será sempre fundamental investigar os jogos de poder que permitem às diferentes culturas criarem seus critérios para estabelecer sua concepção de saúde e de doenças, bem como os usos e abusos a que ambas estão sujeitas criando culturas próprias e refletindo sobre os corpos.

Lugar comum ou sintonia com as perspectivas da Organização Mundial da Saúde ${ }^{3}$, seria afirmar que a saúde é muito mais do que a ausência de doenças. Constitui-se em um direito muito mais amplo de afirmação da vida e de construção da cultura, na qual o ser humano tenha acesso não apenas às suas condições básicas (de alimentação, moradia, higiene, educação, trabalho, lazer, prática de esportes e acesso ao conhecimento e tratamentos médicos disponíveis na sociedade em que vive), mas que haja espaço para

3 "A saúde no entender da OMS é um estado de completo bem-estar físico, mental e social. A $32^{\mathrm{a}}$ Assembléia Geral da OMS estabelece 10 pontos básicos que devem ser incluídos entre os cuidados primários da saúde: educação sobre os principais problemas de saúde, prevenção e controle dos mesmos; alimentação e nutrição adequadas; água de boa qualidade; saneamento básico; cuidados de saúde materno-infantil; imunização contra as principais doenças infecto-contagiososas; prevenção e controle de endemias locais; tratamento de doenças e traumatismos; promoção de saúde mental; fornecimento de medicamentos básicos".(CUNHA, 1987, p.15)

Movimento, Porto Alegre, v.12, n. 03, p. 73-96, setembro/dezembro de 2006. 
seus desejos e vontades. É preciso mais do que sobreviver para criar cultura, o retalho da roupa de trabalho precisa aliar-se ao colorido das roupas de festa.

Segundo Silvana Goellner, (2003, p. 28):

\begin{abstract}
[...] pensar o corpo como algo produzido na e pela cultura é, simultaneamente, um desafio e uma necessidade. Um desafio porque rompe, de certa forma, com o olhar naturalista sobre o qual muitas vezes o corpo é observado, explicado, classificado e tratado. Uma necessidade porque ao desnaturalizá-lo revela, sobretudo, que o corpo é histórico.
\end{abstract}

Maurice Merleau-Ponty (1999, p. 122) contribui afirmando que o ser humano só poderá existir se compreender que a comunicação com o mundo e com o todo só se realiza pelo corpo e no corpo, pois ele "é o veículo do ser no mundo".O corpo assimila e retrata tudo que vivencia, costumes da época, pressões sociais e econômicas. Nesse sentido, Denise Sant'Anna (2001, p. 3) acrescenta que o corpo é:

Território tanto biológico quanto simbólico, processador de virtualidades infindáveis, campo de forças que não cessa de inquietação e confronto, o corpo talvez seja o mais belo traço de memória da vida [...] Pesquisar seus segredos é perceber o quanto é vão separar a obra da natureza daquela realizada pelos homens: na verdade, um corpo é sempre biocultural, tanto em seu nível genético, quanto em sua expressão oral e gestual. Sendo uma evidência que acompanha todo ser humano, do seu nascimento à sua morte, o corpo é, contudo, finito, sujeito a transformações nem sempre desejáveis ou previsiveis. Ao longo dos anos mudam suas formas, seu peso, seu funcionamento e seus ritmos.

Movimento, Porto Alegre, v.12, n. 03, p. 73-96, setembro/dezembro de 2006. 
O corpo concebido dentro de um contexto sócio-cultural, no qual está inserido, não pode mais ser visto a partir de seus aspectos biológicos dissociados das questões culturais e simbólicas que o constitui na história. Para Jocimar Daólio (2004), mais importante que cunhar uma nova terminologia que apresente a educação física em sua dimensão cultural é considerar que esta área não pode prescindir de pensar o corpo humano desde uma dimensão de pluralidade, alteridade e diferenças culturais, porque em suas palavras:

\section{O profissional da educação física não atua so- bre o corpo ou com o movimento em si, não trabalha com o esporte em si, não lida com a ginástica em si. Ele trata do ser humano nas suas manifestações culturais relacionadas ao corpo e aos movimentos humanos, historica- mente definidos [...]. (DAÓLIO, 2004, p.3).}

Com base nessa compreensão ampla da educação física postulamos o campo do lazer como uma das possibilidades de estabelecer a continuidade de nossa costura do corpo da saúde e da cultura, mediando o processo como o fio de alinhavar e possivelmente costurar processos dinâmicos e plurais.

\section{CORPO E SAÚDE ALINHAVADOS PELO LAZER CONSTRUINDO CULTURA}

Entre outras áreas de produção de conhecimento, interrogamos as possibilidades do lazer constituir-se em saber capaz de acolher os reclamos de um direito à saúde integral (física, metal, social e cultural) e que possa fazer frente a uma economia que a falsifica e se apropria dos corpos e da cultura ao transformar produções simbólicas de sentido para a existência plena em meras mercadorias.

O lazer vivido em uma sociedade urbana, complexa, informatizada e às vezes refém dos apelos simbólicos das várias mídias, representa um grande desafio diante do que já se experi- 
mentou em sociedades mais simples, comunitárias, rurais, préindustriais e longe dos atuais processos de globalização. Em outros momentos históricos o tempo do lazer e o do trabalho estavam intimamente ligados, conforme afirma Roberto Boullón (2004, p. 20): “[...] no início, nas comunidades primitivas, o jogo uniu-se ao descanso físico e mesmo ao trabalho durante os festejos religiosos e mágicos que a ele se misturavam."

Segundo Witold Rybczynski, a partir do século XIX fica demarcada uma nova forma de vivenciar o lazer, os tempos e lugares para este começam a ser separados não apenas do tempo e espaço do trabalho, mas de outros aspectos constituintes da cultura. Nas palavras do autor:

$$
\begin{aligned}
& \text { [...] não era o lazer misturado ao trabalho nem } \\
& \text { vice-versa. O lazer da classe média, que foi sur- } \\
& \text { gindo e influenciou toda a sociedade, tinha algo } \\
& \text { de novo: um limite de hora e lugar bem marca- } \\
& \text { dos, separando diversão e trabalho. Mais do que } \\
& \text { qualquer outra coisa, esse limite - do qual o } \\
& \text { fim de semana é exemplo - veio caracterizar o } \\
& \text { lazer moderno.(RYBCZYNSKI, 2000, p. 113). }
\end{aligned}
$$

Essa novidade dos últimos séculos e de modo acelerado nas últimas décadas do século passado reflete na organização cultural como uma espécie de fragmentação que não atinge apenas tempo e lugar, mas que alcança indelevelmente as pessoas e suas relações. O ser humano, cada vez mais alvo das especializações da ciência e da medicina, tem seu corpo ultra-dividido (para não dizer esquartejado) num processo de aumento significativo de suas impossibilidades de ser visto integralmente. Seu corpo é exigido a restringir-se à sua doença ou ao seu trabalho ou às suas frustrações ou aos seus sonhos e remetido a um forte isolamento. O corpo fraturado pela economia de mercado neo-liberal pode ter novidades e dificuldades em sair do controle das dispersas micro-redes de poder, contudo, na sua condição de humanidade a transgressão e resistência não são de todo eliminadas, podem até ser dificultadas.

Movimento, Porto Alegre, v.12, n. 03, p. 73-96, setembro/dezembro de 2006. 
Em estreita relação com outras esferas de produção cultural como o trabalho, a educação, a saúde também o lazer pode tanto exercer valores questionadores de uma cultura dominante, assim como, pode sofrer influências da estrutura social vigente. Nessa contradição os retalhos com suas marcas simbólicas desafiam a um movimento resistente de pensar o lazer como ludicidade, prazerosidade, fruição, gratuidade, ócio, contemplação nas brechas da vida e nos limites da morte, no tempo liberado das obrigações ou no tempo burlado, "roubado", como se escondesse uma "molecagem". Por isso, o corpo insiste em trabalhar, mas também jogar futebol uma vez por semana, em adoecer, mas não deixar de trançar o corpo e os pés na balada, em cuidar crianças, mas divertir-se com os brinquedos e brincadeiras sem compromisso (de nossa parte), fantasia delas é claro.

Enfim, por mais que a economia capitalista insista em afirmar que "tempo é dinheiro" ou demonizar o "desperdício" no que tange ao tempo dedicado às tarefas que resultam em acumulação de capital, ou ainda impingir para o vocabulário cotidiano expressões que desqualifiquem tempos e atitudes de lazer, (a exemplo de "não fizemos nada, apenas jogamos conversa fora"; "perdi tempo brincando com as crianças e agora tenho que recuperar fazendo..."; "gastei minhas energias no passeio do fim de semana e não descansei para enfrentar o trabalho... "; " "é uma loucura, mas vou com vocês e depois eu me viro"; "agora/hoje/nesse mês... não posso me dar ao luxo de parar só depois que terminar tudo"). O que se percebe é que o imaginário social vai sendo alimentado por idéias, crenças, medos e mitos que revelam acima de tudo um corpo inquieto e divido, porém ativo, tanto em sua subversão como em sua busca por "desculpar-se" de seus atos diante do sagrado chronos - deus engolidor de seus filhos e filhas.

O fio de costura aqui proposto, o Lazer, por sua ampla dimensão cultural, pode propiciar ao corpo tanto o descanso, quanto o divertimento e o desenvolvimento individual e social empoderando-o para tecer contra-símbolos culturais. Christianne

Movimento, Porto Alegre, v.12, n. 03, p. 73-96, setembro/dezembro de 2006. 
Gomes (2004) reitera esta perspectiva ao afirmar o grande potencial do lazer enquanto uma das esferas de construção dinâmica da cultura mediatizados pelo "[...] jogo, a brincadeira, a festa, o passeio, a viagem, o esporte e também as formas de arte (pintura, escultura, literatura, dança, teatro, música, cinema), dentre várias outras possibilidades" (GOMES, 2004, p. 124), incluindo o ócio nesse elenco.

O sociólogo Joffre Dumazedier (1980) ao estudar o lazer na sociedade moderna e industrializada apresentou uma abrangente classificação do lazer, distinguindo-o segundo os interesses que mobilizam as pessoas. Interesse a seu ver deveria ser entendido como o "conhecimento que está enraizado na sensibilidade, na cultura vivida" (DUMAZEDIER, 1980, p. 32), fato este que pode promover maior preferência entre uma atividade de conteúdos físico-esportivos ou manuais ou artísticos ou intelectuais ou sociais $^{4}$ por parte das pessoas.

No processo de escolha entra tanto a subjetividade de cada um como as referências simbólicas predominantes que a circunscrevem a um marco cultural contextualizado em suas dimensões de idade, de classe, de gênero, de etnia, de crença embora nenhum destes tenha caráter fixo a despeito das normatividades sociais que para alcançar coesão social tendem a padronizações rígidas. Nelson Marcellino (1996) considera que o ideal seria vivenciar atividades que abrangessem os vários interesses, porém, adverte para a realidade de que as pessoas geralmente ficam restritas à vivência de apenas um campo específico, muitas vezes por não terem opções ou oportunidades de conhecimento de outros conteúdos.

O lazer não pode ser visto apenas como um conjunto de atividades, mesmo que se considere um amplo espectro destas, é importante ressaltar que no próprio modo de envolvimento das

${ }^{4}$ A estes cinco conteúdos culturais de interesse no lazer, Luiz Otávio Camargo (1992) acrescenta o turístico.

Movimento, Porto Alegre, v.12, n. 03, p. 73-96, setembro/dezembro de 2006. 
pessoas, sua adesão, segundo Joffre Dumazedier (1980), pode se dar de modos diferenciados, isto é, em três perspectivas, a da prática, do conhecimento ou da fruição (assistência) e estes modos podem ser caracterizados como elementar (conformismo), médio (criticidade) e superior (criatividade). Nesse sentido, Nelson Marcellino (1996) propõe que uma atividade de lazer não é ativa ou passiva em si, mas depende do nível de envolvimento em que ela se desenvolve. Por exemplo, pode-se participar da assistência de um dos conteúdos culturais do lazer de modo crítico e criativo, por conseguinte gerando um estado de saúde integral que fortalece as pessoas a vivenciar e re-inventar seus processos culturais de dignidade, de cidadania, de auto-estima etc.

Cabe considerar também que a possibilidade de convivência com os vários aspectos do lazer, no entanto, nem sempre faz parte da vida das pessoas, pois algumas barreiras sócio-culturais, que podem existir entre as diversas classes sociais (interclasses) ou dentro das próprias classes sociais (intraclasses), mostram-se como fatores limitantes a esse acesso. Nem todas as pessoas, por exemplo, têm a possibilidade de acesso aos equipamentos de lazer, seja por falta de condições econômicas que limitam o próprio acesso, seja por falta de políticas públicas de lazer, ou ainda, por deficiência no planejamento de uma política de animação sócio-cultural para esses espaços e de uma democratização cultural. (MARCELLINO, 1996).

Ao tecer a cultura, apresentando o lazer como uma das possibilidades de contribuir para a saúde das pessoas, não resta dúvida que se precisa, por um lado de questionamentos aos processos instituídos de forma excludente e por outro lado, o resgate ou a visibilização das ações culturais vividas pelos grupos sociais sem que estes as reconheçam como lazer.

No estudo denominando "Festa no Pedaço" José Guilherme Magnani (2003) observa que as comunidades de periferia envolvidas em uma rotina de trabalho muito pesada criam seus espaços e

Movimento, Porto Alegre, v.12, n. 03, p. 73-96, setembro/dezembro de 2006. 
tempos "para respirar" e para afirmar que estão vivos. Nestes, experimentando festas e formas diferenciadas de lazer, mas não a nomeiam como tal em vista de uma grande distancia do que a mídia veicula como sendo lazer - pacotes prontos de atividades e bem separados do cotidiano do trabalho. Para este autor "o momento do lazer - instante de esquecimento das dificuldades do dia-a-dia - é também aquele momento e oportunidade do encontro, do estabelecimento de laços, do reforço dos vínculos de lealdade e reciprocidade, da construção das diferenciações" (MAGNANI, 1988, p. 39) e não necessariamente a realização de uma atividade específica, por exemplo.

A festa, trazida aqui apenas como um dos exemplos, constitui uma das experiências de lazer experimentadas pelas sociedades humanas, muito antes das atuais convenções e reduções do tema. Por isso, vale resgatar dela o caráter "coletivo extraordinário, extratemporal e extralógico", como sublinha Léa Freitas Perez:

\begin{abstract}
[...] a condição da festa é dada pela confluência de três elementos fundamentais interdependentes um do outro, que se con-fundem um com os outros, a saber: um grupo em estado de exaltação [...] que consagra sua reunião a alguém ou a alguma coisa [...] e que, assim procedendo, liberta-se das amarras da temporalidade linear e da lógica da utilidade e do cálculo, pois a festa é uma sucessão de instantes fugidios, presididos pela lógica do excesso, do dispêndio, da exacerbação, pela dilapidação. Em resumo: a festa instaura e constitui um outro mundo, uma outra forma de experienciar a vida social, marcada pelo lúdico, pela exaltação dos sentidos e das emoções (PEREZ, 2002, p. 190).
\end{abstract}

A festa, dentre outros momentos de lazer, possui um forte poder de renovação da esperança, das forças individuais e de reafirmação dos anseios cotidianos de mudança. Isso porque cada qual traz para o momento coletivo o seu melhor desejo e contribui

Movimento, Porto Alegre, v.12, n. 03, p. 73-96, setembro/dezembro de 2006. 
com o mais significativo aporte de seus bens básicos, criando a fartura da comida, da bebida, da música, da alegria - experiências essas não possíveis no dia-a-dia. A festa aparece como uma "suspensão do real" capaz de revigorar a força, para retornar a ele e resgatar-lhe a dignidade. Um tom de resistência preside a festa, pois a esperança de transformação do cotidiano opressor é sinalizada na alegria e no prazer que ocupam os momentos coletivos do encontro.

Segundo Nelson Marcellino (1996, p. 96), a festa enquadrase nesse universo lúdico, com possibilidades de denúncia da realidade e de subversão da ordem vigente, considerando que “[...] embora não de modo exclusivo, é particularmente no tempo de lazer que são vivenciadas situações geradoras de valores que poderiam ser chamados de "revolucionários". Provavelmente por conta desse caráter de subversão do real, muitas pessoas insistem em questionar as festas de "severinos e severinas" que vivem a fartura da comida, da bebida e da alegria, gastando seus parcos recursos para passar fome o resto do mês. Não entendem que tais eventos são afirmações de um desejo que não sucumbe às necessidades ainda não satisfeitas; ao contrário, transcendeas. (SAMPAIO, 2004).

Dessa maneira, a festa percebida como uma possibilidade de lazer, em resistência às amarras do cotidiano ditado pelo mundo do trabalho, apresenta-se como elemento questionador da perspectiva compensatória do lazer, na medida em que este, na lógica do mercado, representa um prêmio para quem cumpriu as exigências de inserção e status. Ou para aqueles que, submissos à ordem vigente, esperam que "beneméritos detentores do poder" lhe permitam um tempo livre. Ou, ainda, utilizado como instrumento importante para manter o controle das massas empobrecidas a quem são oferecidos, circunstancialmente, espaços de divertimento, de modo que elas não se apercebam do real esquecimento a que estão submetidas no cotidiano do trabalho, dos salários, da saúde, da educação e da moradia. Ou, por fim, como espaço para as classes

Movimento, Porto Alegre, v.12, n. 03, p. 73-96, setembro/dezembro de 2006. 
médias manterem sua auto-percepção de estar inseridas e em ascensão no mundo dos sonhos de consumo. Cada uma dessas modalidades de condução do lazer tem embutidas as suas formas de alienação e de controle dos grupos sociais.

O ritmo do trabalho e das demais obrigações sociais, movidos por um sistema econômico excludente e competitivo pode levar as pessoas a não valorizar devidamente o lazer como seu direito à prazerosidade, à felicidade e mesmo à sua condição de saúde. Por isso, consideramos fundamental garantir tanto uma visão mais ampla do lazer que transcenda a esta de um conjunto de atividades recreativas de caráter compensatório, quanto o acesso das pessoas aos bens culturais disponíveis na sociedade que aparentemente parece pertencer a poucos, aqueles já "liberados" do mundo das necessidades básicas.

Essa possibilidade, crítica e criativa de encarar o lazer permite simultaneamente assumir a bandeira deste como um direito inalienável e fundamental (à saúde física, emocional, social, cultural... integral) assim como, comprometer-se com mudanças de paradigmas na percepção do econômico, do social, do cultural, do político, do ambiental entre outros. Para tanto, é preciso que se considere que mudança de percepção atinge profundamente nossa visão antropológica.

Nesse caminho, aponto três contribuições que podem se constituir em retalhos de cultura que ao serem arrumados para esta colcha que estamos tecendo pareçam tecidos muito novos (certamente, não para todos). Refiro as noções de interdependência e conexidade advindas das teorias da complexidade, as de relações sociais de poder provenientes das teorias de gênero e as de necessidade e desejo como elementos integrados na existência humana.

A primeira, pensa o ecossistema em sua dimensão interdependente e complexa, no qual o ser humano inclui-se, não como superior, mas como distinto, inaugurando uma nova percepção que propõe relações de conexidade entre seres vivos diferen-

Movimento, Porto Alegre, v.12, n. 03, p. 73-96, setembro/dezembro de 2006. 
tes na perspectiva de redes. Desse modo, a relação com a "natureza" ou áreas de conservação podem em muito extrapolar ao lazer oferecido pelo mercado do "turismo ecológico", redimensionando uma relação importante à existência humana sem aprisioná-la a um elenco de atividades vendidas como mercadorias de lazer moderno, radical, de aventura e de ruptura com a realidade cotidiana rotineira do cumprir obrigações.

A segunda, com suas ênfases no questionamento das relações sociais assimétricas entre homens e mulheres, na demarcação da não homogeneidade destes grupos sociais, na afirmação da pluralidade de feminilidades e masculinidades, agregando-se a essa reflexão a constatação das assimetrias étnicas e de classes sociais, trouxe à tona que as desigualdades sociais baseadas nas denominadas diferenças de ordem biológica são construções sóciohistóricas e culturais que foram sendo "naturalizadas" ao longo da história, obscurecendo os jogos de poder embutidos nestas descrições de relações.

Dessa maneira, várias barreiras de gênero, de etnia, de classe precisam ser revisadas no lazer que poucas vezes é usufruído, por exemplo, pelas mulheres tomadas por jornadas duplas de trabalho, ou pelo racismo cultural sutilmente difundido no imaginário social de que a população negra em descanso ou atividades de lazer apenas confirma a tese de que "são preguiçosos por natureza" e por isso fracassam na inserção no sistema capitalista. O lazer pode ser um espaço significativo para reverter essa concepção cultural preconceituosa e excludente "com o lazer e sua efetiva participação cultural abre-se a possibilidade da conquista da autonomia e de exercício da cidadania, [...] como caminho para a consolidação de uma sociedade mais justa." (STOPPA, 2005, p. 31)

A terceira refere-se a uma concepção reducionista que preside muito das visões antropológicas ao considerar o binômio necessidade-desejo como aspectos contrapostos e hierarquicamente subordinados, descaracterizando-lhe a simultaneidade na constru-

Movimento, Porto Alegre, v.12, n. 03, p. 73-96, setembro/dezembro de 2006. 
ção do ser humano. Isso porque, não raras vezes, o lazer aparece como parte do desejo humano e, portanto, podendo ser descartado, adiado ou manipulado. Hugo Assmann (1994, p. 56) insiste que "somos, ao mesmo tempo, seres com necessidades e seres desejantes", considerando um equívoco hierarquizar necessidades e desejos, como se tais dimensões fossem passíveis de, satisfeitas as primeiras, liberar as pessoas ao desfrute daquilo que seria "supérfluo" - o desejo. A simultaneidade de necessidades e desejos é condição básica para a compreensão da complexa experiência de tornar-se humano e construir cultura.

Na poesia da música brasileira, a juventude afirmou, em alto e bom som: "A gente não quer só comida, a gente quer bebida, diversão e arte. A gente quer viver a vida por inteiro, e não pela metade". ${ }^{5}$ A sede e a fome aqui reclamadas levam a compreender que a existência humana não se reduz a um conjunto de obrigações entremeadas de descansos e de alguns motivos de riso e descontração - na qualidade de permissão inevitável diante de uma suposta "fraqueza" desse ser que não sabe só produzir sem fazer paradas de afirmação da vida, que são completamente "inúteis" à lógica da economia de mercado, pois não acumulam, nem reforçam a exclusão e interrompem os chamados (pelo sistema) sacrifícios necessários. (SAMPAIO, 2006)

As vivências do lazer pensadas como momentos de saúde do corpo resultam em movimento transgressor quando pensamos na cultura dominante marcada pela economia de mercado que conhecendo muito bem a capacidade criadora de cultura dos desejos procura reduzi-los ao simples consumo de mercadorias. Outro resultado dessa leitura da economia de mercado acerca do lazer pode ser evidenciado na redução da necessidade ao desejo. Mais do que muitos de seus críticos, o mercado é sagaz ao reconhecer que o desejo não pode ser desprezado na compreensão do huma-

${ }^{5}$ Comida, canção de autoria dos Titãs.

Movimento, Porto Alegre, v.12, n. 03, p. 73-96, setembro/dezembro de 2006. 
no, apropriando-se dessa dimensão e fazendo com que a diferença entre ambos se extinga. Além disso, expropriando do ser humano a amplitude do que representa o desejo na construção de sua identidade e relacionalidade. Posto que o desejo é básico para a criação humana de cultura, de transformação do que está no horizonte imaginado como realidade plausível de experimentação. A expropriação do desejo significa instrumentalização a serviço do mercado e, conseqüentemente, redução do desejo humano ao consumo de mercadorias, entre elas, muitas vezes, o lazer.

Na qualidade de bem de consumo, o lazer ficará à mercê das regras que regem a mercadoria, ou seja, não é possibilidade socializada, e sim privatizada, sendo escasso o acesso para quem não possui a moeda de compra, ou implicará aquisição de mercadorias de qualidades diversas, compatíveis com seu custo. Nessa restrição a que o lazer tem sido instado a submeter-se, retira-se dele sua força de direito cidadão o qual independe de mérito. Segundo Johanne Madsen (1999, p.96):

O lazer é um dos direitos sociais assegurados no artigo $6^{\circ}$ da Constituição da República Federativa do Brasil, ao lado de saúde, educação e outros, mas, mesmo sendo um direito legalmente garantido, sua consecução encontra-se distante da realidade, principalmente por três fatores determinantes. O primeiro refere-se à falta de acesso da maior parte da população ao lazer, o segundo, à pequena oferta de ações de educação para e pelo lazer, e o terceiro, à escassez de profissionais capacitados para o gerenciamento e a execução das atividades.

Contudo, para que seja possível uma democratização cultural, no âmbito do lazer, é preciso que vários fatores contribuam para a superação das práticas conformistas e alienadas, comandadas e manipuladas pelo mercado (lazer mercadoria), transcendendo em direção a práticas de lazer em níveis críticos de análise e

Movimento, Porto Alegre, v.12, n. 03, p. 73-96, setembro/dezembro de 2006. 
criativos em busca de novos caminhos para a transformação e a humanização das relações.

Não se pode dar às costas ao sistema de mercado, mas é preciso se valer dele em suas conquistas, apropriar-se do possível e reverter o jogo. Considerando importante a reorganização simbólica de vários espaços ocupados pela economia de mercado e seu apelo ao consumo, Edmur Stoppa (2005, p. 57) afirma que:

Em nosso país, atualmente, um exemplo dessa situação pode ser encontrado dentro dos quatro elementos do hip-hop, como na música dos grupos de rap, que, ao mesmo tempo em que contestam a mídia, posicionando-se contra a televisão e o mercado fonográfico representado pelas grandes gravadoras, buscam espaços alternativos, como a formação de produtoras. de selos musicais independentes, de revistas e fanzines ${ }^{6}$ que garantam por outros meios não só a distribuição do trabalho, mas o controle sobre a produção, de modo a propiciar um espaço que dê visibilidade aos seus trabalhos, pois só assim, de acordo com os participantes, seria possivel lutar, fazer-se ouvir, ou ainda negociar as causas que julgam importantes.

Esse movimento de contestação que não se resume em críticas ao sistema pode resultar em criação de espaços em que o lazer contribua fortemente por meio de seu duplo aspecto educativo como uma fonte de vivência significativa, a qual confere sentido à vida das pessoas e concomitantemente é um processo de desenvolvimento pessoal e social de valores cujo potencial pode transformar a realidade. Esta perspectiva pode ser confirmada através da prazerosidade experimentada e do conhecimento cidadão que resulta de sua vivência. A ênfase em uma concepção de Lazer que

${ }^{6}$ Publicação alternativa fora dos padrões convencionais, dedicada a assuntos de música popular.

Movimento, Porto Alegre, v.12, n. 03, p. 73-96, setembro/dezembro de 2006. 
coopere para os processos de uma saúde integral, de afirmação da dignidade e direitos fundamentais da pessoa e principalmente, de autonomia crítica e criativa diante dos impasses da realidade é fundamental para desenvolver atividades de Lazer e cuidado do corpo como um processo cultural que resgate a pessoa de suas múltiplas fragmentações.

Entre outros aspectos que o leitor e a leitora certamente acrescentarão para os arremates nessa colcha tecida com pedaços de história, de vida, de imaginação, de sonhos, de proposições de criticas e criativas mediando no gesto de dizer a palavra e tecer a cultura afirmei a alteridade e a convivialidade como momentos fortes a inaugurar novos processos culturais. Dessa maneira, desejo finalizar com pontos de reticências (quem sabe de alinhavos) e não dar por terminada a colcha de retalhos, mas disponibilizá-la para que os seus retalhos sejam a ela acrescentados.

\footnotetext{
Sewing culture with mediators that unit body, health, and leisure.

Abstract: The metaphor of the patchwork quilt opens up a reflection about bodies that have rolled on the fabrics with their life stories and dribbles to the death, made themselves cozy in the plural experiences, constituting themselves into culture. The words, our patches, they will be among the other languages forms, the great artisans of the dialogue among body, culture, and health. Leisure will be experienced as a line used to tack and to sew relationships, as much by the potential of becoming a culture expression on which the body can experience transgression, as much by, the will to not succumb to the expropriation promoted by the market economy.

Keywords: Mind-body relations. Cultural Characteristics. Quality of life. Leisure activities.
} 


\begin{abstract}
Tejiendo cultura con mediciones que unen cuerpo salud y tiempo libre.

Resumen: La metáfora de la colcha de retales abre

la reflexión acerca de los cuerpos que rozaron en

los tejidos con sus historias de vida y sus fintas a

la muerte, se acogieron en las experiencias plurales, constituyéndose en cultura. Las palabras, nuestros retales, serán entre la demás formas de lenguajes las grandes artesanas del dialogo entre cuerpo, cultura y salud. El tiempo libre se experimentará como un probable hilo que pueda hilvanar y coser relaciones, tanto por el potencial de ser una expresión de la cultura en la cual el cuerpo puede probar el traspaso, como por la expropiación promovida por la economía de mercado.

Palabras clave: Relaciones mente-cuerpo. Características culturales. Calidad de vida. Actividades recreativas.
\end{abstract}

\title{
REFERÊNCIAS
}

ASSMANN, Hugo. Paradigmas educacionais e corporeidade. Piracicaba: UNIMEP, 1994.

BOULLÓN, Roberto C. Atividades turísticas e recreativas: o homem como protagonista. Tradução Maria Elena Ortega Ortiz Assumpção. Bauru: EDUSC, 2004.

CAMARGO, Luiz Otávio. O que é lazer. 3. ed. São Paulo: Brasiliense, 1992.

CASSIRER, Ernst. Antropologia filosófica: ensaio sobre o homem: introdução a uma filosofia da cultura humana. São Paulo: Mestre JOU, 1972.

CUNHA, Bruno Carlos de Almeida. Saúde: a prioridade esquecida. Petrópolis, RJ: Vozes, 1987.

DAÓLIO, Jocimar. Educação Física e o conceito de cultura. Campinas: Autores Associados, 2004.

DUMAZEDIER, Joffre. Valores e conteúdos culturais do lazer. Tradução Regina Maria Vieira. São Paulo: SESC, 1980

GOELLNER, Silvana V. A produção cultural do corpo. IN: LOURO, Guacira L., NECKEL, Jane F. e GOELLNER, Silvana V. (org.) Corpo gênero e sexualidade, um debate contemporâneo na educação. Petrópolis, RJ Vozes, 2003. p. 28-40.

Movimento, Porto Alegre, v.12, n. 03, p. 73-96, setembro/dezembro de 2006. 
GOMES, Christianne L. Lazer: concepções. In: GOMES, Christianne L. (org.). Dicionário crítico do lazer. Belo Horizonte: Autentica 2004. p. 119-125.

HELLER, Ágnes. Historia y futuro: sobrevivirá la modernidad? Barcelona: Península, 1991.

LE GOFF, Jacques et al. As doenças têm história. Lisboa: Terramar, 1985.

MADSEN, Johanne E. H. Lazer na empresa e lazer pela empresa: a associação da marca da empresa ao lazer e à qualidade de vida. In: MARCELLINO, Nelson C. (org.). Lazer \& empresa. Campinas, SP: Papirus, 1999. p. 95-111.

MAGNANI, José Guilherme C. Festa no pedaço: cultura popular e lazer na cidade. São Paulo: HUCITEC, 2003.

MAGNANI, José Guilherme C. Lazer dos trabalhadores. Revista São Paulo em Perspectiva. São Paulo, v.2, n.3, p. 37-39, jul./set. 1988.

MARCELLINO, Nelson C. Estudos do lazer: uma introdução. Campinas, SP: Autores Associados, 1996.

MERLEAU-PONTY, Maurice. Fenomenologia da percepção. 2. ed. São Paulo: Martins Fontes, 1999

PEREZ, Léa F.. Antropologia das efervescências coletivas. In: PASSOS, M. (org.). A Festa na vida: significado e imagens. Petrópolis, RJ: Vozes, 2002.

PESSOA, Fernando. Melhores poemas de Fernando Pessoa: Seleção Teresa Rita Lopes. 9. ed. São Paulo: Global, 1997.

RYBCZYNSKI, Witold. Esperando o fim de semana. Tradução de Beatriz Horta. Rio de Janeiro: Record, 2000.

SAMPAIO, Tânia Mara V. Conhecimento científico: capacidade humana de intervir reinventando e revertendo a sina Severina. In: MOREIRA, Wagner Wey; SIMÕES, Regina (org.). Educação Física: intervenção e conhecimento científico. Piracicaba: UNIMEP, 2004.

SAMPAIO, Tânia Mara V. Corpo ativo e religião. IN: MOREIRA, Wagner Wey (org.). Século XXI: a era do corpo ativo. Campinas, SP: Papirus, 2006. p. 63- 89

SANT'ANNA, Denise B.. É Possível Realizar uma História do Corpo? In: SOARES, Carmem (org.). Corpo e história. Campinas: Autores Associados, 2001. p. 3-23. STOPPA, Edmur Antonio. "Tá ligado mano": o hip-hop como lazer e busca da cidadania. 2005. 143f. Tese (Doutorado em Educação Física)-Faculdade de Educação Física. Universidade Estadual de Campinas, Campinas, 2005.

WITTGENSTEIN, Ludwig. Tractatus lógico-philosophicus. Tradução de José Arthur Giannotti. São Paulo: Editora Nacional, 1968.

Recebido em: 30.06 .2006 Aprovado em: 29.09.2006

Movimento, Porto Alegre, v.12, n. 03, p. 73-96, setembro/dezembro de 2006. 